\title{
Internet resources for religious studies
}

\author{
By Jeffrey A. Coon
}

\section{Resources from listservs to clearinghouses}

$\mathbf{T}$ he Internet provides access to a multitude of resources relevant to religious studies. An invaluable introduction is Michael Strangelove's The Electric Mystic's Guide to the Internet(Ottawa, Ontario: M. Strangelove, 1993). It is a nearly comprehensive directory of religion-related online discussion groups, electronic serials, file archives and other resources. The current version is available via FTP from the node PANDA1.UOTTAWA.CA in the directory /pub/religion/ as the files:

electric-mystics-guide-v1.txt electric-mystics-guide-v3.txt

You can also receive The Electric Mystic's Guide via e-mail by sending the following message to LISTSERV@UOTTAWA:

get mystics v1-txt

get mystics $v 3$-txt

\section{Locating online discussion groups}

A thorough listing of major online discussion groups in all disciplines is Diane Kovacs' $D i$ rectory of Scholarly Electronic Conferences (Kent, Ohio: Kent State University Libraries). The religious studies section describes over 25 groups. To retrieve it, FTP KSUVXA.KENT.EDU and get the file ACADLIST.FILE 4 from the $/ 1 \mathrm{i}^{-}$ brary/ directory. You may also wish to get the ACADLIST.README file, which contains helpful explanatory notes. Alternatively, send the following e-mail message to LISTSERV@ KENTVM:

get acadlist.file4

get acadlist.readme
Another way to locate groups is to send the command LIST GLOBAL /*** (where (*** $^{* *}$ is subject keyword such as RELIGION) as an email message to any valid listserv address. The result will be a list of discussion groups whose titles or descriptions contain that keyword, sent to you as an e-mail message.

\section{Selected online discussion groups}

Following are a few examples of the wide variety of groups available. Most can be joined by sending the e-mail message "SUBSCRIBE Groupname YourName" to LISTSERV@NODE, where NODE is the part of the group address after the "@" symbol. For example, to subscribe to AIBI-L@UOTTAWA, Jane Doe would send the e-mail message: "SUBSCRIBE AIBI-L Jane Doe" to LISTSERV@UOTTAWA. Exceptions to this procedure are noted.

As indicated, some discussion groups also appear as newsgroups on Usenet, a network available at many universities.

- AIBI-L@UOTTAWA or AIBIL@ACADVM1. UOTTAWA.CA focuses on the computerized analysis of Biblical texts.

- AMERCATH@UKCC or AMERCATH@ UKCC.UKY.EDU provides a forum for discussion among scholars and teachers of the history of American Catholicism.

- ATLANTIS@HARVARDA or ATLANTIS@ HARVARDA.HARVARD.EDU (American Theological Library Association Networked Theological Information Service) promotes professional communication among members of ATLA and other interested persons. To request subscription, contact CWILL@HARVARDA or CWILL@HARVARDA.HARVARD.EDU.

- BUDDHA-L@ULKYVM or BUDDHA-L@ ULKYVM.LOUISVILLE.EDU is an open forum 
for exchange of information and views on topics related to Buddhism and Buddhist studies.

- ELENCHUS@UOTTAWA or ELENCHUS@ ACADVM1.UOTTAWA.CA discusses Christian thought and literature from $\mathrm{AD} 100$ to $\mathrm{AD} 500$. Messages in English or French are welcome.

- FEMREL-L@MIZZOU1 or FEMRELMIZZOU1.MISSOURI.EDU encourages discussion on women and religion and feminist theology.

- IOUDAIOS@YORKVM1 or IOUDAIOS@ VM1.YORKU.CA concentrates on discussion of first-century Judaism and Christian origins, particularly the works of Philo of Alexandria and Flavius Josephus. Knowledge of Greek is helpful. ("IOUDAIOS" is Greek for "Jew".)

- ISLAM-L@ULKYVM or ISLAM-L@ ULKYVM.LOUISVILLE.EDU carries non-sectarian discussion and debate for scholars and students of the history of Islam.

- JUDAICA@TAUNIVM or JUDAICA@ TAUNIVM.TAU.AC.IL invites exchange of information and discussion of work in progress, electronic applications and new approaches which relate to Judaic studies. Participation by a broad audience is encouraged.

- OBJ-REL@EMUVM1 or OBJREL@ EMUVM1.CC.EMORY.EDU seeks objective discussions of religion and its roles in society.

- RELIGION@HARVARDA Or RELIGION@ HARVARDA.HARVARD.EDU is sponsored by the Harvard Center for the Study of World Religions. Its purpose is to foster scholarly discussion of the historical or comparative study and teaching of religions. (It is not a forum for personal statements of faith.)

- SSREL-L@UTKVM1 or SSREL-L@ UTKVM1.UTK.EDU (Scientific Study of Religion) focuses on the study of religion by scholars in various disciplines.

\section{Usenet newsgroups}

Usenet is an international computer network available at many universities. Contact your computer center for further information on access. As noted, some newsgroups also exist as Internet discussion groups. Note: Not all newsgroups are available at all sites. Usenet news groups on religion are: alt.atheism, alt.hindu, clari.news.religion, rec.music. christian, soc.culture.jewish, soc.religion. christian, soc.religion.christian.biblestudy, soc.religion.eastern, soc.religion. islam (also RELIGION-ISLAM-REQUEST@NCAR. UCAR.EDU), soc.religion.quaker, talk.origins (creation/evolution discussions), talk.religion. misc, talk.religion.newage.

\section{Electronic journals and newsletters}

There are a growing number of joumals and newsletters available through the Internet. Typically, they are retrievable through FTP or email, but increasingly they are also available through GOPHER.

- Bryn Mawr Classical Review publishes reviews of current work in Greek and Roman studies. To subscribe, send the e-mail message "SUBSCRIBE BMCR-L" to LISTSERV@ CC.BRYNMAWR.EDU.

- A Byte of Torab and A Megabyte of Torah are companion publications. Byte is a weekly newsletter providing analysis of Torah verses; Megabyte is a more detailed monthly publication. To subscribe, send the e-mail message "SUBSCRIBE BYTETORAH" to LISTSERV@ ISRAEL.NYSERNET.ORG.

- IOUDAIOS Review is the review journal of IOUDAIOS@YORKVM1, the discussion group on first-century Judaism and Christian origins. It is distributed to members of IOUDAIOS. (See "Selected online discussion groups" above.)

- Offline is a column by Robert Kraft which has appeared for a number of years in The Bulletin of the Council of Societies for the Study of Religion and in Religious Studies Neus. It concentrates on the use of computers in religious studies. Distribution is to members of IOUDAIOS.

- Religious Studies Publications Joumal CONTENTS intends to serve as a comprehensive source of information on pedagogical and research resources in religious studies. It electronically archives reviews, abstracts, conference papers, theses and dissertations, bibliographies and other documents and announces their availability to subscribers. It is not a discussion group. To subscribe, send the e-mail message "SUBSCRIBE CONTENTS YourName" to LISTSERV@UOTTAWA or LISTSERV@ ACADVM1.UOTTAWA.CA. To receive full texts of reviews and book notes announced in Religious Studies Publications Journal-CONTENTS, send the message "SUBSCRIBE REVIEWL YourName" to the same addresses.

\section{Other resources}

- CCAT GOPHER: Point your GOPHER at CCAT.SAS.UPENN.EDU (or telnet to that address and login as "gopher"). The University of Pennsylvania Humanities Department and Center for Computer Analysis of Texts (CCAT) pro- 


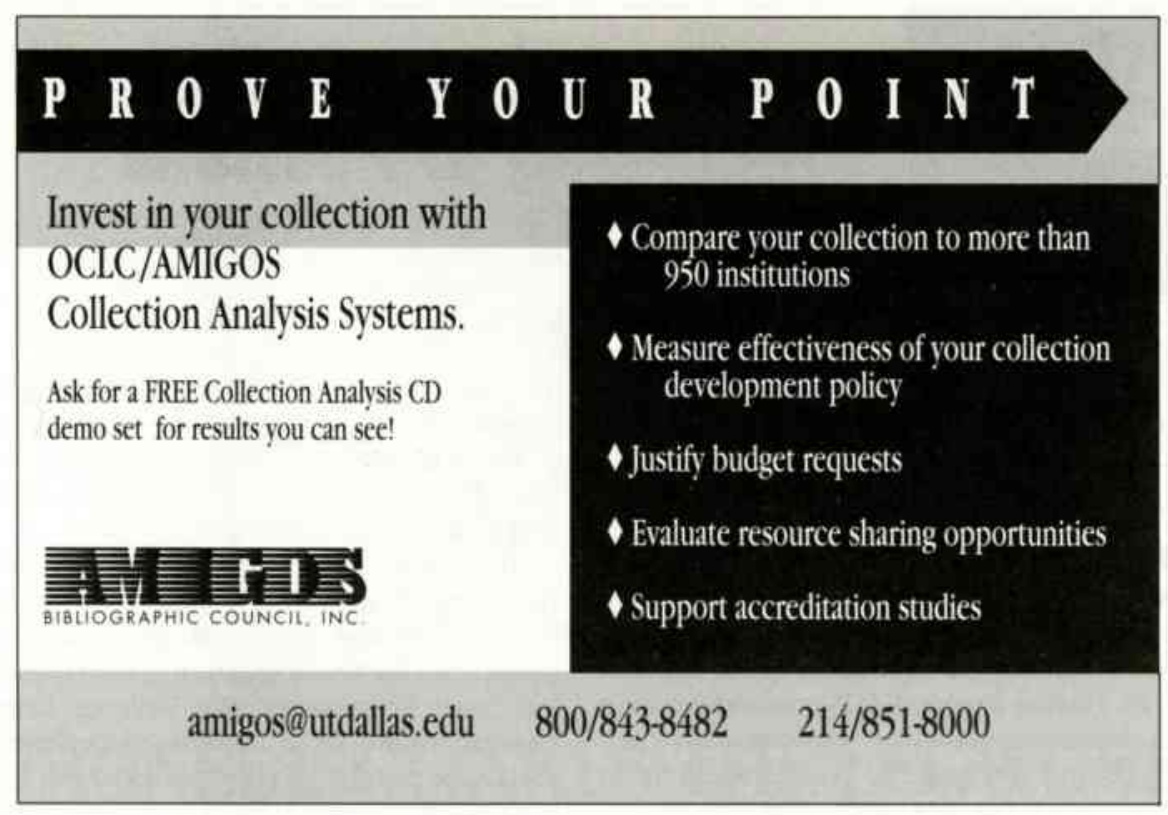

vide a collection of humanities course materials and electronic texts through this GOPHER, including sacred texts which can be searched electronically and retrieved, course syllabi, glossaries, essays, and various information files. It also provides a wide variety of Internet-related documents and connections to other humanities-related GOPHERs.

- Johns Hopkins University Press Online Database: Tables of contents and abstracts are available several months in advance for Journal of Early Christian Studies and other journals. To access them, FTP JHUNIX.HCF.JHU. EDU. Login as "anonymous" and give your Internet address as the password. Get the jcearl-f and jcearl-p files from the /JHU_Press/.zjournals/ class/ directory. These files are also available through the GOPHER at JHUNIX.HCF.JHU.EDU.

- Electronic Buddhist Archives: A worldwide repository of files for researchers of Buddhism, Taoism, and other Asian religions. FTP WUARCHIVE.WUSTL.EDU, login as "anonymous", and explore the directory /doc/ coombspapers/otherarchives/electronicbuddhist-archives/.

- JewishNet-The Global Jewish Information Network Project: An electronic clearing- house for a wide variety of information relevant to Jewish studies. You can connect to online catalogs at Jewish libraries or find out about other file servers, online discussion groups, archives and documents. Telnet to VMS.HUJI.AC.IL and login as "jewishnet".

- Locating sacred texts and related software: Access ARCHIE on a GOPHER or telnet to ARCHIE and search for PROG ${ }^{* * *}$, where ${ }^{* * *}$ is the name of a text, such as Bible or Quran. You will receive a listing of related resources. PROG BIBLE, for example, produces a long listing of Bible text files and study software which can be retrieved via FTP.

- Cruising the FTP sites: FTP PANDA1 UOTTAWA.CA and go to the /pub/religion/ directory. This is the home of the CONTENTS Project archives, including bibliographies, a directory of religious studies scholars, reviews of online discussion groups, theses, dissertations and more. Get the file ftp-index.txt for a helpful overview. FTP ISRAEL.NYSERNET.ORG for a vast archive of material on contemporary Judaism and Israel. Included are the complete text of the Tanach and accompanying commentary, online discussion group archives, Hebrew fonts and other software. 